\title{
La disputa del mercado fronterizo 1960-1983
}

\author{
Alejandro Mungaray Lagarda \\ Patricia Moctezuma Mungaray \\ Escuela de Economía \\ Universidad Autónoma de Baja California
}

\begin{abstract}
Resumen
El presente trabajo es un esbozo de la evolución de la lucha que por el mercado fronterizo han venido realizando los industriales nacionales en relación con la política aduanera diferencial que ha imperado para México y la frontera, así como en relación a las políticas mexicanas de integración del mercado fronterizo. Se destaca el uso de las devaluaciones como mecanismos de competencia e integración, las cuales han afectado profundamente el poder adquisitivo de los trabajadores fronterizos, y reflejan a su vez la incapacidad del industrial mexicano para competir por el mercado fronterizo con productos más baratos, mejores y en cantidad suficiente. Esto quiere decir que cuando el mercado fronterizo favorezca a los industriales y a la burguesía intermediaria de la frontera, será porque estos han afectado irremediablemente a la clase trabajadora mexicana de la frontera; y aquí, no se podrá culpar al imperialismo.
\end{abstract}

Palabras clave: mercado fronterizo, PRONAF, proteccionismo nacional, libre comercio, zona libre, inflación.

\begin{abstract}
This project tries to offer a sketch that shows us how the struggle performed by domestic industry companies has evolved in order to recruit the border market, in relation to the differentiated customs policies that have dominated Mexico and its Northern border, as well as the Mexican policies established to integrate the border market. It highlights the use of devaluations as competition and integration mechanisms, same that have critically affected the purchasing power of the Mexican border workers and showing that Mexican industrial men do not have the capability to catch the border market with cheaper and better products with enough quality. This means that when the border market favors industry companies and the intermediary middle class of the border, it will be when they have definitely affected the Mexican working class from the border zone. In this case, imperialism could not be blamed.
\end{abstract}

Keywords: border market, PRONAF, national protectionism, free trade, free zone, inflation. 


\title{
LA DISPUTA DEL MERCADO FRONTERIZO. 1960-1983
}

\author{
Por \\ Alejandro Mungaray Lagarda \\ Economista. Profesor-investigador de la Facultad de Economía \\ de la UNAM y profesor-becario de la Escuela de Economía de \\ la Universidad Autónoma de Baja California, en Tijuana \\ y \\ Patricia Moctezuma Mungaray \\ Economista. Investigadora de la Escuela de Economía de la \\ Universidad Autónoma de Baja California, en Tijuana
}

\section{INTRODUCCION.}

El estudio de la zona fronteriza del norte de México, se ha convertido en un tema de relevante actualidad en el marco de la recomposición de las relaciones capitalistas (asociación y/o competencia) entre México y Estados Unidos. Aunque los trabajos pioneros datan de fines del siglo pasado, es a partir de principios de los sesentas cuando toman un carácter más definido y, junto con la mayoría de los trabajos que desde entonces y hasta la fecha se han realizado por numerosos investigadores, coinciden en señalar como problema de importancia central, la escasa vinculación de la economía fronteriza con el resto de la economía nacional y su creciente vinculación y dependencia respecto a la economía norteamericana ${ }^{1}$. Más aún, muchos de los recientes cambios en la política económica mexicana respecto a la zona fronteriza, han estado imbuidos de un alto sentido nacionalista, producto del reconocimiento de la importancia de tal problemática.

Por otra parte, esta escasa vinculación de las regiones fronterizas con el resto de la economía nacional, ha sido entendida también como la pérdida de un espacio de realización para la circulación de mercancías producidas por los empresarios mexicanos y a la vez, como un mercado crecientemente vinculado al ciclo de reproducción del capital norteamericano ${ }^{2}$, e inclusive,

\footnotetext{
${ }^{1}$ Por ejempio, ver los trabajos de Antonio Bermúdez, El Rescate del Mercado Fronterizo, Eufesa, México, 1966; Victor Urquidi y Sofía Méndez, "Importancia Económica de la Zona Fronteriza del Norte de México", en Foro Internacional, Vol. XVI, No. 2, México, octubrediciembre de 1975, pp. 149-174; Joaquín Xiráo y Miguel Díaz. Nuestra Dependencia Fronteriza, F.C.E., México, 1976; José Luis Fernández Santiesteban, "Al. zunas consideraciones sobre los programas de industrialización y de comercialización fronteriza, sus efectos y perspectivas", en R. Gonzălez Salazar (Comp.), La Frontera del Norte. Integración y Desarrollo, El Colegio de México, México 1981; Romea Flores Caballero, Evolución de la Frontera Norte., Centro de Investigaciones Económicas de la Facultad de Economía, UANL, Monterrey. 1982; Jesús Tamayo y José Luis Fernández, Zonas Fronterizas (México-Estados Unidos), CIDE, México, 1983 y R.J. Ramírez Acosta, "La Conflictiva Zona Libre de Baja California", Economia Informa, No. 110, México, noviembre de 1983, pp. 29.31 entre otros. Un interesante trabajo realizado desde el lado norteamericano, es el de Oscar J. Martínez, Ciudad Juárez: el auge de una ciudad fronteriza a partir de 1848. F.C.E., México, 1982.

IRaúl Fernáñdez, La Frontera México-Estados Unidos. Un estudio socioeconómico, Terranova, México, 1980.
} 
como una zona propicia para la industrialización de bienes cuyo destino es en lo fundamental el mercado mundial. ${ }^{3}$

Como se ve, resulta altamente sugestiva la discusión señalada, considerando que no es una discusión abstracta y que refleja una realidad vigente y sumamente compleja, sólo que vista desde enfoques analíticos totalmente diferentes.

En este trabajo se vislumbran algunos elementos relevantes para el estudio del desarrollo del capitalismo en la zona fronteriza del norte de México, en el contexto del desarrollo del capitalismo en México y en Estados Unidos. Para esto es preferible recurrir al enfoque de la totalidad en el afán de ubicar el contenido de la discusión nacionalista como un elemento interpretativo (aunque parcial) en la explicación de la lucha intercapitalista por el mercado fronterizo.

\section{PROTECCIONISMO NACIONAL Y LIBRE COMERCIO FRONTERIZO.}

\section{EI contexto latinoamericano}

Hasta antes de la crisis de 1929, en América Latina prevalece la idea de que el desarrollo del capitalismo ocurriría en virtud de la magnitud del financiamiento externo que a través de la inversión extranjera en los sectores productivos, realizaran los empresarios extranjeros. Con el crack se puede comprobar la enorme vulnerabilidad del desarrollo capitalista latinoamericano al fincarse en el crecimiento de las exportaciones al mercado mundial, en función de la demanda de materias primas que requieren los empresarios de los países imperialistas. Con matices distintos, esta situación prosigue hasta la II Guerra Mundial, donde cristaliza una industrialización espontánea en algunos países latinoamericanos, especialmente en México, debido a la creciente demanda de bienes de consumo manufacturados no duraderos, proveniente de las potencias beligerantes, principalmente de Estados Unidos. Tras esta experiencia "espontánea" surge en 1948 la CEPAL, que institucionalizó su funcionamiento como elemento promotor y planificador de la industrialización latinoamericana, incorporándose en un proceso que, aunque lento y sin organización, ya venía dandose de suyo.

Así, en el primer informe de la CEPAL, en 1949, se lanza la convocatoria a impedir que los precios internacionales de las mercancías arrebaten los frutos de la productividad lograda en los paíseś caracterizados como periféricos, dada la estructura económica internacional. Para ello se propone el impulso de la industrialización como alternativa para retener los frutos de la productividad lograda internamente, creando, debido al mismo marco internacional, una estructura proteccionista para tal fin.

3 Folker Fröbel, Jurgen Hinrichs y Otto Kreye, La Nueva División Intemacional del Trabajo, Siglo XXI eds. México, 1981; Jean Revel Mouroz, "La Frontera México-Estados Unidos, Mexicanización e Internacionalización", en Cuademos de Marcha, segunda época, año III, núm. 6, México, nov-dic. de 1982, pp. 7-16,y Alejandro Mungaray, "División Internacional del Trabajo y Automatización de la Producción: el futuro de las Maquiladoras, en Investigación Económica, Vol. XLII, número 164, Méxiço, abril-junio de 1983, pp. 231-253. 
En efecto, dado que la división internacional del trabajo se establece en función de la estructura productiva determinante en los diferentes países, el papel que corresponde a las economías "periféricas" debido al carácter especializado de su estructura productiva, es el de producir y exportar materias primas y alimentos a todo el sistema, como "el instrumento para conseguir (. . ) las importaciones de bienes manufacturados" requeridos por la demanda interna. 4

De otra forma, el desarrollo económico de estas economías se basa en el crecimiento de la producción del sector primario y de las importaciones y, dada la coexistencia con economías con un alto grado de desarrollo capitalista que basan su crecimiento en una estructura económica diversificada, se genera una situación de subordinación y dependencia a través de las relaciones de intercambio que las burguesías latinoamericanas mantienen con las de los países capitalistas más desarrollados.

Como se ve, desde esta perspectiva la problemática central de las economías latinoamericanas descansa en la flagrante y desigual distribución del ingreso prevaleciente, así como en el deterioro de los términos de intercambio que tanto afecta el desarrollo de la empresa capitalista latinoamericana.

Consecuentemente con el diagnóstico y por lo menos en su etapa inicial, esto es, hasta mediados de los sesentas, la idea cepalina de la industrialización es eminentemente nacionalista. Así, sustituir importaciones de productos manufacturados que antes se importaban, y proteger el mercado para estos nuevos productos prohibiendo la importación de similares extranjeros aunque estos fueran más competitivos, son medidas fuertemente impregnadas de nacionalismo, en el sentido de proteger el desarrollo del naciente sector industrial de la burguesía.

Una actitud similar se observa respecto a la inversión extranjera, ya que ésta sóio se concibe como un elemento compatible con el desarrollo capitalista latinoamericano, bajo la forma de financiamiento gubernamental a través de los organismos internacionales creados para tal efecto (BID, BIRF, AID, etc.) Sin embargo, el flujo masivo de capitales privados extranjeros abriría un gran campo de conflictos al interior de la CEPAL, ya que en tanto algunos apoyaron las políticas que favorecían la entrada masiva de capitales, "otros se mantuvieron fieles a la idea de continuar el desarrollo con la decidida participación del Estado y la burguesía nacional, apoyados por los organismos financieros internacionales". 5 De cualquier forma, todo parece indicar que el nacionalismo proteccionista paulatinamente se va haciendo más compatible con la inversión extranjera directa, en tanto ésta contribuya al logro de los objetivos de política económica de los distintos estados nacionales.

\footnotetext{
4Octavio Rodríguez, la Teoria del Subdesarrollo de la CEP.AL. Siglo XXI eds., México, 1980, pp. 27 y 309. 5 Francisco Rodríguez Garza, "Reflexiones en torno al pensamiento económico de América Latina", en Teoria y Política Año IV No. 9; México, enero-marzo de 1983, pp. 35-68: 42.
} 


\section{El contexto mexicano}

En México, el proceso de industrialización basado en la sustitución de importaciones, se realizó en dos etapas: la de productos de consumo final (1936-1952) y la de bienes de consumo durable (1953-1965). Sólo a partir de entonces, aunque de forma endeble, se ha iniciado la sustitución de bienes intermedios y de capital, jugando a la fecha un papel secundario, 6

Por lo que se refiere a la industrialización realizada durante la primera etapa, se caracteriza en su conjunto por la existencia de una baja composición orgánica de capital; por una abundante disponibilidad de fuerza de trabajo a bajos salarios; por el predominio de tecnología industrial de tipo tradicional, y por el uso de insumos y materias primas en gran parte de origen nacional. En consecuencia, los niveles de rentabilidad fueron comparativamente altos. 7

En este proceso, el Estado puede considerarse como un promotor directo del desarrollo industrial, no tan sólo mediante la creación de una amplia infraestructura industrial y agrícola, sino también mediante la implementación de una decidida política de promoción industrial basada en un fuerte proteccionismo que impuso altos aranceles y licencias de importación a todos los productos provenientes del comercio exterior, cuya introducción al mercado nacional significara peligro para los productos nacionales.

No obstante los altos niveles de rentabilidad en la industria, estos proceden en lo fundamental de un mercado interno protegido que, por lo demás, es necesario para fomentar una industria que por sus elevados costos, no puede competir con sus productos en el mercado internacional. "En estas condiciones, la capacidad del sector para autofinanciar las importaciones que requería de maquinaria y materias primas, era muy limitada e insuficiente". . De esta forma, el sector capitalista de la agricultura asumió la función de proveer las divisas necesarias para la importación de los medios de producción requeridos (capital constante fijo más precisamente). No en balde, la política oficial de la época señala que las exportaciones de café, hortalizas y algodón, debían compensar las "importaciones de productos básicos y dejar remanentes para financiar otras importaciones de bienes de capital" requeridas para impulsar la industrialización de México. 9 Este papel coincide con una situación en el mercado mundial en que los precios internacionales de los productos primarios son altamente favorables. Y el fin de esta situación coincide con el agotamiento de la industrialización ligera, a mediados de los años sesenta.

6Raúl Olmedo, México: Economia de Ficción, Grijalbo, México, 1983, p. 53.

7 Miguel Angel Rivera Ríos y Pedro Gómez Sánchez, "México: acumulación y crisis en la década del setenta", en Teoría y Política. Año 1, No. 2, México, oct-dic, de 1980, pp. 73-120: 78.

${ }^{8} \mathrm{Raúl}$ Olmedo, op. cit. p. 54.

${ }^{9}$ Alejandro Mungaray L. Un enfoque económico sobre el carácter politico del reparto agrario y el desarrollo capitalista de la agricultura Mexicana: 1930-1970. Inédito, México, 1982, pp, 19-20. 


\section{El contexto fronterizo}

Estudios recientes sobre la dinámica de crecimiento de la economía de la frontera norte de México, coinciden en señalar como explicación fundamental de la escasa integración de ésta con la economía nacional, la adopción de un esquema de política aduanera y arancelaria diferenciado a nivel fronterizo y a nivel nacional, tanto para el tratamiento de las corrientes de mercancías importadas, como para el tratamiento de la inversión extranjera directa. 10

Aquí conviene aclarar que el trasfondo de la escasa integración de la economía fronteriza a la nacional, se refiere al reducido aprovechamiento del mercado fronterizo por parte de los productores nacionales debido a la gran preferencia que tienen todos los tipos y estratos de consumo fronterizo respecto a los bienes y servicios norteamericanos. Esta preferencia viene dada tanto por razones históricas como lo son la tradición, el hábito, etc., como por razones eminentemente prácticas como mejor precio y mayor calidad, variedad y oportunidad en la adquisición de bienes americanos en comparación con una escasa oferta de los bienes y servicios requeridos de procedencia nacional. A esto debe añadirse la distante localización geográfica de la industria nacional y la ausencia o limitada presencia de ésta en la frontera.

Así, siguiendo a Fernández, la pregunta obligada respecto a la competencia intercapitalista internacional en la frontera es: ¿por qué la política comercial en la frontera no ha sido eficaz, en términos de su objetivo consistente en sustituir importaciones en el mercado fronterizo por producción nacional? 11

A reserva de una respuesta de más detalle, el razonamiento que parece ser el más objetivo es el que parte de que la apertura comercial de la franja fronteriza, esto es, de la política comercial de libre comercio que prevalece históricamente en las franjas fronterizas, se perfila como la única forma de abrir mayores posibilidades a una industrialización que no puede provenir del impulso de la burguesía nacional, a la vez que como una forma de resolución al problema del abasto nacional al mercado local de bienes de consumo generalizado. Lo importante de la apertura comercial de la frontera es que desde una perspectiva nacionalista, sirve como elemento de atracción de grupos poblacionales que le dan una cohesión político-cultural a la frontera.

En efecto, dada la lejanía de la región fronteriza respecto de los centros industriales del país y sus no muy acentuados vínculos comerciales con los mismos, las relaciones económicas con la pujante Norteamérica se hacen paulatinamente más intensas. Ya a finales del siglo pasado, algunas de las ciudades mexicanas que pasaban a ser los nuevos puertos fronterizos se convir-

\footnotetext{
10 José Luis Fernández S. op. cit., p. $255-56$ y R. J. Ramírez A, op. cit. p. 29.

11J. L. Fernández, op. cit, p. 255.
} 
tieron en importantes centros de comercio. También existen otros centros urbanos de menor importancia que, dada la intesificación de las relaciones comerciales entre habitantes y empresarios de ciudades norteamericanas como San Diego, y de ciudades un tanto retiradas de la frontera como Ensenada, B.C., se convierten en prominentes puertos fronterizos en el transcurso de unos cuantos años: es el caso de Tijuana.

De hecho, y hasta finales de la década de los treintas, justo cuando el capitalismo en México inicia su etapa de consolidación madura, en la franja fronteriza la situación es de distanciamiento dada la insuficiencia de la industria nacional para cubrir la demanda del mercado local, tanto la de bienes de consumo duraderos y básicos, como la de insumos para las actividades productivas. 12

Las zonas y perímetros libres son un mecanismo de desarrollo capitalista de la frontera, en tanto configuran un límite político y cohesionado, coherente con el desarrollo global del capitalismo mexicano que ocurre en la época de Cárdenas. De hecho, es éste quien con un alto sentido nacionalista y con una amplia comprensión de la importancia del establecimiento de los límites geograficos del poder político, es decir, de la territorialidad del Estado, impulsa políticas para poblar con mayor intensidad la frontera y así proteger y ampliar el mercado nacional. La colonización del valle de Mexicali, B.C., es una buena prueba de ello.

Por otra parte, las condiciones favorables que ofrece el sur de Estados Unidos, tanto para cubrir la demanda local como para absorber los productos y servicios que pudiera ofrecer la economía regional, estimulan el distanciamiento entre el mercado fronterizo y la burguesía del interior del país, estimulando a su vez el crecimiento de una burguesía fronteriza fuertemente arraigada a las actividades comerciales (burguesía intermediadora), así como una gran interdependencia entre la poblacion de ambas fronteras, sobre todo en lo referente a hábitos de consumo, comportamientos sociales y patrones culturales.

Con esto no se afirma que la población fronteriza mexicana haya adoptado plenamente los hábitos y costumbres norteamericanas, de la misma manera que no es posible afirmar que la población fronteriza norteamericana ha adoptado los hábitos y costumbre de vida mexicanas: de ahí la interdependencia.

Ahora bien, el tipo de desarrollo capitalista fronterizo, aunque se hace más intenso a partir de fines de los cincuentas, está indisolublemente ligado a sus orígenes. Así, dado que las fronteras surgen en términos económicos, como puertos de comercio y abastos de los estados y regiones fronterizas, las bases de una estructura industrial son, en la mayoría de los casos, débiles.

12PRI, Plan Básico para el Estado de Baja California 1983-1989. CEPES, Mexicali, junio de 1983, p. 5. 
No se puede decir lo mismo de la estructura comercial que es sumamente ágil e intensa, y caracteriza desde sus inicios el desarrollo capitalista de la zona fronteriza del norte de México.

\section{Significado de la política diferencial.}

Para la economía en su conjunto, pero principalmente para la economía fronteriza, el papel de las relaciones económicas internacionales reviste particular interés.

Sin entrar en suposiciones de ningún tipo, el desarrollo de las distintas economías nacionales se da en estrecha relación al desarrollo de la economía mundial. Luego entonces, los acontecimientos de una nación no son ajenos ni están separados del contexto mundial. De la misma forma, los acontecimientos en las regiones de una nación tampoco se disocian del contexto nacional. En el caso de la economía fronteriza, esto resulta mucha más evidente; sólo que aquí la interacción de distintos contextos nacionales es la que actúa sobre la geografía socioeconómica de la frontera. De aquí entonces que la región fronteriza no puede ser definida tan sólo en cuanto a su desarrollo actual que de por sí es particular. Más bien,la definición debe ocurrir observando los elementos que llevan a conformar una región de tal tipo y las características que le son asignadas en términos de la relación/confrontación entre dos naciones con grados distintos de desarrollo capitalista y, más precisamente, entre los grupos empresariales que en ellos se desenvuelven.

De esta forma, en el contexto del desarrollo capitalista moderno, las relaciones internacionales entre los países, reflejadas en su frontera común, máxime cuando estos países tienen un grado de desarrollo capitalista desigual, son relaciones intercapitalistas de asociación y/o competencia, donde el proteccionismo o la apertura de la economía en su conjunto o en sus regiones, ocurre en función de cómo los intereses de las burguesías nacionales se vean favorecidos o, por lo menos, no afectados.

Así, se puede afirmar que en el marco de la competencia intercapitalista internacional el recurso del comercio exterior permite a los empresarios por una parte, obtener maquinaria y materias primas que abaraten los costos en el nivel adecuado para producir competitivamente $y$, por otra, obtener niveles de ganancia por encima de la media, al vender la producción por encima de su costo aunque por abajo del precio de los competidores.

$\mathrm{Al}$ incrementarse la ganacia, se dinamiza el proceso de crecimiento de las empresas, a la vez que se rompen los márgenes nacionales de actuación para las mismas. Tal puede ser el caso de un país con alto grado de desarrollo capitalista como Estados Unidos. Sin embargo, así como éstos pueden recurrir al mecanismo del comercio exterior para colocar sus excedentes y/o acceder a nuevos mercados, sobre todo si los productos son altamente competitivos; por la misma razón, las políticas proteccionistas pueden nulifi- 
car el mecanismo de la competitividad de las mercancías del exterior para proteger el desarrollo de los proyectos nacionales, como resulta ser el caso del proyecto de la industrialización mexicana.

El proteccionismo resulta porque es tendencia inevitable de las empresas con alto desarrollo tecnológico tener que recurrir, en primera instancia, al comercio exterior. Esto, a la vez que puede estimular una respuesta innovadora en las empresas nacionales sujetas a la competencia, puede frenarlas, desviarlas o inclusive, arruinarlas. Y el peligro que trae consigo cualquiera de estas posibles alternativas para las empresas nacionales es lo que genera los procesos proteccionistas ahí donde hay procesos iniciados e intereses capitalistas nacionales que proteger.

Ahora bien, la creciente implementación de políticas proteccionistas incide en forma determinante en la relocalización especial de la industria, acentuándose con esto la extensión y homogeneización del capitalismo de regiones con alto desarrollo capitalista hacia regiones donde, aun cuando existe un menor desarrollo capitalista, existen mejores condiciones para desarrollar las actividades productivas de las empresas internacionales, de manera que la operación de capital sea más rentable.

Sintéticamente, la política comercial diferencial a nivel nacional y fronterizo resulta del hecho de que una vez iniciado el proceso de industrialización, y vía sustitución de importaciones en México, las corrientes de mercancías provenientes del comercio exterior que pudieran afectar directa o indirectamente el mercado para los mismos productores, pero producidos por empresarios nacionales, fueron sujetas a un estricto control aduanero. Como la restricción de estas corrientes comerciales viene a afectar el nivel de ganancia de algunas importantes firmas extranjeras, entonces éstas se inscriben en el marco de legalidad institucional y se convierten en empresas "nacionales" que operan sin restricciones y acceden a los mercados protegidos gozando de las mismas prerrogativas que cualquier otro empresario nacional, y con ventajas sobre sus márgenes de ganancia gracias a la reducción de costos, los estímulos fiscales, etc. Es el caso de las empresas conocidas como transnacionales.

Por otra parte, dado el arraigo fronterizo a patrones de consumo y mercancías norteamericanos, y la insuficiencia de la industria nacional ya no tan sólo para competir en cualquier sentido con estos productos, sino para abastecer regular y oportunamente la frontera (escasa capacidad de oferta) con aquellos productos que sí son competitivos, la política comercial de la frontera es de libre cambio, favoreciéndose así importantes núcleos de trabajadores, pero principalmente de empresarios del sector comercio y servicios. De la misma forma como no hay grandes restricciones a las importaciones, la inversión extranjera directa asume otras características distintas a la realizada en el interior del país. Es el caso de la industria maquiladora que goza de una fórmula de estímulos más abierta y liberal, sobre todo en la participación de capital extranjero en el capital social, que es hasta de $100 \%$. 
Sin embargo, el nacionalismo no está ausente en el régimen arancelario de este tipo de empresas, ya que su producción debe ser totalmente exportada, evitándose así la afectacion de los intereses de las burguesías productoras e intermediadoras que actúan en la frontera.

\section{LA LUCHA POR LA FRONTERA: MECANISMOS NACIONALES DE INTEGRACION}

A diferencia de la población de la Frontera Norte de México que, según el estudio de Urquidi y Méndez 13 , se caracteriza por tener un nivel de bienestar promedio más alto que el resto del país, la población de la frontera sur de Estados Unidos, según el estudio de Clement ${ }^{14}$, se caracteriza por contar con un nivel de bienestar promedio inferior al de los estados en que se ubican.

En el esquema de desigualdad del desarrollo capitalista descrito anteriormente, esta caracterización parece fuera de lógica. Sin embargo, la lógica se recupera por dos hechos que son, en realidad, partes de uno solo. En primer lugar, los puertos fronterizos norteamericanos se han convertido, en virtud de las restricciones del mercado interno estadounidense y por iniciativa de las grandes sociedades comerciales de ese país, "en polos comerciales capaces de absorber a la clientela mexicana (en una zona de 1,000 a $1,500 \mathrm{~km}$ de profundidad), consumidora de vestimentas, productos industrializados y bienes de equipamiento hogareño". 15

Ello no significa que su desarrollo económico haya sido tan intenso como el de las grandes zonas industriales norteamericanas. Más bien, y gracias al comercio, se ha desarrollado una burguesía intermediadora de los grandes grupos industriales del interior del pais, que concurren al mercado con una gran variedad de mercancías y precios sumamente atractivos y en volúmenes suficientes.

En segundo lugar, la población mexicana, al tener acceso a los bienes y servicios norteamericanos ofrecidos en las condiciones señaladas, y que son mejores que aquellas en las que se les brindan los productos de procedencia nacional, ven mejorar, con el nivel de ingreso de que disponen, sus posibilidades de acceder a bienes que en condiciones normales no es posible hacerlo.

Así, la relación de interdependencia entre la circulación de mercancías y su consumo es sumamente intensa entre las dos fronteras, que se convierten por tal razón en un único contexto fronterizo caracterizado por una

\footnotetext{
13 V. Urquidi y S. Méndez, op. cit.

14 Norris Clement, "Perspectivas sobre el desarrollo económico de la región fronteriza del sudoeate de Estados Unidos", en M. Ojeda (Comp.), Administración del desarrollo de la Frontera Norte. El Colegio de México, México, 1982.

15J. Revel-Mouroz, op. cit., p. 10.
} 
fuerte presencia de la burguesía comercial que lo ha convertido en un espacio natural de su actuación como realizadora de mercancías producidas en sitios alejados de ésta.

De este modo, la relación de competencia y asociación intercapitalista que se da en la frontera se puede ubicar en dos niveles: a) la relación de competencia entre burguesías comerciales mexicanas y norteamericanas por conquistar el consumo fronterizo, b) la relación de competencia entre las burguesías industriales por conquistar, por intermediación de los distribuidores comerciales, el espacio de realización fronterizo. Dados los niveles de productividad en que operan ambas industrias y el tipo de economías de escala logradas, han sido los sectores empresariales estadounidenses quienes mayormente han salido beneficiados. Sin embargo, en la relación de asociación implícita en la de competencia, muchos han sido los empresarios fronterizos mexicanos favorecidos con altos niveles de ganancia al operar como intermediarios directos e indirectos de la producción estadounidense al mercado estable de la frontera y a un mercado flotante que acude desde el interior del país a consumir bienes norteamericanos que son más baratos y de mejor calidad que los ofrecidos nacionalmente.

Ahora bien, la lucha por el mercado fronterizo emprendida por la burguesía mexicana, que ha sido escondida bajo el manto de la integración nacional de la frontera e impulsada por medídas de política económica, se ha venido dando con mayor intensidad a partir de principios de los sesentas con la elaboración del PRONAF (Programa Nacional Fronterizo) y hasta hoy con las graves medidas devaluatorias que en lo esencial no hacen más que avalar el destemple de una industria nacional que, ineficiente y protegida, no avanzó jamás en la restructuración de su estructura técnico-productiva, de tal manera que pudiera acceder con sus productos a disputar competitivamente los mercados y en especial el fronterizo.

\section{El programa nacional fronterizo (PRONAF)}

La franja fronteriza se ha convertido en un reto para las dos economías que la comparten $y$, dado que sus características son tajantes, marcadas por su desarrollo capitalista desigual, los mecanismos implementados para lograr la conquista de los mercados fronterizos reflejan cierta diferenciación en las distintas etapas de su desarrollo.

A nivel nacional la zona fronteriza del norte de México representa $2,597 \mathrm{~km}$ que atraviesan 6 estados, 35 municipios y 34 poblaciones limítrofes 16 . Por tanto, dada la importancia geográfica de este mercado, las actividades que se han implementado para integrarlas al resto de la economía en el sentido ya descrito, han representado el principal objetivo de las diferentes administraciones gubernamentales mexicanas.

16A. J. Bermídez, op. cit., p. 17. 
Ya en 1939 se establecían los mecanismos necesarios para intentar resolver este problema mediante el establecimiento de las zonas y perímetros libres de Baja California y parcial de Sonora. Sin embargo, sólo a partir de la década 1960, la implementación de mecanismos para la conquista del mercado fronterizo tiende a vincular éstos con la producción generada por las industrias nacionales.

El primer mecanismo implementado fue el PRONAF, que representa el primer intento planificado de integración económica, política y cultural a nivel fronterizo. Así, con la participación del Estado como principal ente impulsor de las actividades de programación e inversión, se le dan al PRONAF los siguientes objetivos: a) elevar el nivel de vida de los fronterizos a través de la implementación de fuentes de trabajo, b) creación de servicios, y c) elevación de los niveles de cultura.

Desde el punto de vista económico, el objetivo principal es impulsar la concurrencia de productos nacionales a la franja fronteriza. Ahora bien, el principal obstáculo que se presenta es que la concurrencia de productos norteamericanos importados es parte de la cotidianeidad del consumidor fronterizo, siendo la competencia, por tanto, marcadamente discriminatoria para los productos nacionales que, en calidad y precio, no logran ser más competitivos que los norteamericanos. En el caso de los bienes de capital, éstos proceden sin discusión del exterior en su totalidad.

En la etapa inicial del PRONAF, 1961-1965, se desarrolla la implementación de los medios e instrumentos necesarios para impulsar las activi-

dades destinadas para la integración fronteriza a la estructura productiva nacional. De esta forma el presupuesto se destinó heterogéneamente a los municipios que conforman la zona fronteriza. Así, inicialmente se invirtió en infraestructura para modificar las condiciones físicas de las ciudades fronterizas, correspondiendo a Cd. Juárez, Chih. el $31.16 \%$ o de la inversión total del programa. La siguieron Ensenada, B.C. y Nogales, Son. con el 16 \% y $16.6 \%$ respectivamente; Tijuana, B.C. con el $10.2 \%$ y Mexicali, B.C. y Piedras Negras, Coah. con el $6.3 \%$ y el $6.9 \%$ o de los 41 millones de pesos de la inversión inicial total. 17

La implementación de este programa contempló la instrumentación de una politica fiscal que estimulo a los industriales y comerciantes a concurrir a la frontera. Para ello se estableció la excención del pago sobre ingresos mercantiles $(1.8 \%$ o $)$ y el descuento del $25 \%$ o sobre las cuotas de fletes de ferrocarril. Como resultado de los anteriores estímulos, durante este período se dio un incremento considerable de productos nacionales enviados a la frontera, ya que de 434 millones que se vendían en 1960 , se pasó a 1.595 millones en 1965. Esto contribuyó a que el índice de retención de ingresos en favor de los empresarios fronterizos se incrementara pasando de $38.8 \%$

17 Ibid, p. 35 
en 1961, a 40.9 \% en 1965. Así, coyunturalmente, esto representó para el industrial nacional lograr la apropiación de mayores niveles de ganancia debido al creciente consumo de productos nacionales en la franja fronteriza.

Por otra parte, en 1963 el gobierno de California emprende actividades de reforzamiento en las localidades fronterizas, en el sentido de que siendo este estado uno de los más ampliamente desarrollados industrialmente en los Estados Unidos, aprovecha su cercanía con los estados fronterizos mexicanos donde comparativamente el nivel de ingreso es menor, para impulsar la generación de nuevas ramas de comercio y producción aprovechando las mercancías defectuosas y los bienes usados desechados en buen estado por los consumidores estadounidenses. Esto viene a mejorar las condiciones de vida del habitante fronterizo que empieza a tener acceso a productos usados que, sin embargo, le brindan los mismos servicios que le brindaría un producto nuevo y que le cuesta mucho menos. Así, en la frontera se hacen comunes las "tiendas de segunda" que venden ropa, artículos eléctricos, muebles usados, etc., y los "lotes" de carros usados, generalizándose lo que despectivamente se ha llamado "economías de desecho".

En cuanto al tipo de consumo realizado por los fronterizos, se tiene que mientras el consumidor fronterizo mexicano destina sus ingresos al consumo de bienes de primera necesidad que encuentra a menores precios en E.U., los norteamericanos demandan sólo servicios y ciertos artículos suntuarios como artesanías, etc. No en balde, en los rubros de bienes de consumo duradero y no duradero, los perímetros libres participan con más del $50 \%$ de las importaciones nacionales; con el $80 \%$ de las importaciones nacionales de legumbres, hortalizas y cereales $y$; con el $70 \%$ de las de maderas y manufacturas de madera. 18

En estos años, que representaron la etapa inicial de la lucha por el mercado fronterizo por parte de los sectores empresariales mexicanos, se manifestó cierta aceptación por los productos nacionales, misma que sin embargo fue mediatizada por el tipo de cambio y los niveles de ingreso de los fronterizos, que les siguen permitiendo tener acceso al consumo de productos importados.

Otro de los resultados del PRONAF fue la proliferación de centros artesanales, que significó una gran concurrencia de productos artesanales a Ia frontera y que han estimulado una creciente afluencia de consumidores norteamericanos. Así, en tanto que antes del PRONAF los mexicanos que cruzaron la frontera crecerían a una tasa promedio anual del $8.7 \%$ o; después de 1962 , este crecimiento descendió al 3.7 \% promedio anual. En cuanto a los norteamericanos que durante esta época cruzaron la frontera, su crecimiento fue casi igual al de los mexicanos. 19

\footnotetext{
$18 \mathrm{~J}$. Tamayo y J. L. Fernández, op. cit., p. 94

190. J. Martínez, op. cit., pp. 162.3
} 
CUADRO 1. Transacciones fronterizas y coeficiente de retención. 19501982. (Millones de dólares)

\begin{tabular}{|c|c|c|c|c|c|}
\hline AÑo & & $\begin{array}{c}\text { A } \\
\text { INGRESOS }\end{array}$ & $\begin{array}{c}\text { B } \\
\text { EGRESOS }\end{array}$ & $\begin{array}{c}\text { C } \\
\text { (A-B) } \\
\text { BALANCE }\end{array}$ & $\begin{array}{c}\text { D } \\
(\mathrm{C} \div \mathrm{A}) \\
\text { COEFICIENTE } \\
\text { RETENCION }\end{array}$ \\
\hline 1950 & (1) & 121.9 & 76.5 & 45.4 & 37.24 \\
\hline 1951 & (1) & 148.3 & 88.4 & 59.9 & 40.39 \\
\hline 1952 & (1) & 163.0 & 101.6 & 61.4 & 37.67 \\
\hline 1953 & (1) & 201.8 & 128.2 & 73.6 & 36.47 \\
\hline 1954 & (1) & 246.7 & 162.2 & 84.5 & 34.25 \\
\hline 1955 & (1) & 261.7 & 151.2 & 110.5 & 42.22 \\
\hline 1956 & (1) & 277.9 & 171.8 & 106.1 & 38.18 \\
\hline 1957 & (1) & 313.3 & 192.6 & 120.7 & 38.53 \\
\hline 1958 & (1) & 315.5 & 188.8 & 126.7 & 40.16 \\
\hline 1959 & (1) & 354.0 & 220.5 & 133.5 & 37.71 \\
\hline 1960 & (1) & 366.0 & 221.0 & 145.0 & 39.62 \\
\hline 1961 & (1) & 392.7 & 242.0 & 150.7 & 38.38 \\
\hline 1962 & (1) & 406.7 & 244.6 & 162.1 & 39.86 \\
\hline 1963 & (1) & 445.9 & 265.2 & 180.7 & 40.52 \\
\hline 1964 & (1) & 463.3 & 276.6 & 186.7 & 40.30 \\
\hline 1965 & (1) & 499.5 & 295.2 & 204.3 & 40.90 \\
\hline 1966 & (1) & 546.6 & 342.8 & 203.8 & 37.29 \\
\hline 1967 & (1) & 599.6 & 359.1 & 240.5 & 40.11 \\
\hline 1968 & (1) & 713.5 & 450.4 & 263.1 & 36.87 \\
\hline 1969 & (1) & 761.2 & 501.5 & 259.7 & 34.12 \\
\hline 1970 & (2) & 878.9 & 585.0 & 283.9 & 32.30 \\
\hline 1971 & (2) & 966.9 & 612.5 & 354.4 & 36.65 \\
\hline 1972 & (2) & $1,057.0$ & 649.3 & 407.7 & 38.59 \\
\hline 1973 & (3) & $1,207.7$ & 695.0 & 512.7 & 42.45 \\
\hline 1974 & (4) & $1,372.9$ & 819.2 & 553.7 & 40.33 \\
\hline 1975 & (4) & $1,541.6$ & 957.7 & 583.9 & 37.87 \\
\hline 1976 & (5) & $1,609.7$ & $1,051.5$ & 558.2 & 34.67 \\
\hline 1977 & (6) & $1,506.3$ & 786.4 & 719.9 & 47.79 \\
\hline 1978 & (7) & $2,363.7$ & $1,631.8$ & 731.9 & 30.96 \\
\hline 1979 & (7) & $2,981.8$ & $2,302.1$ & 679.7 & 27.79 \\
\hline 1980 & (8) & $3,772.1$ & $3,129.5$ & 592.6 & 15.92 \\
\hline 1981 & (9) & $4,770.1$ & $4,584.3$ & 185.8 & 3.8 \\
\hline 1982 & (9) & $4,149.1$ & $3,576.6$ & 572.5 & 13.79 \\
\hline
\end{tabular}

FUENTE:

1) Martínez Oscar J., Cd. Juárez: El auge de una ciudad fronteriza a partir de 1848, F. C. E. México, 1982 p. 161, cuadro VII-1

2) Banco de México, S. A., Indicadores Económicos, Vol. III, No. 2, México, enero de 1975, p. 32.

3) Ibid, Vol. IV, No. 1, diciembre de 1975, p. 38

4) Ibid, Vol. V, No. 5, abril de 1977, p. 46

5) Ibid, Vol. VI, No. 3, febrero de 1978, p. 68

6) Ibid, Cuaderno mensual 85 , diciembre de 1979 , p. 64

7) Ibid, Cuaderno mensual 95 , octubre de 1980 , p. 58

8) Ibid, Cuaderno mensual 121, diciembre de 1982, p. 64

9) Ibid, Cuaderno mensual 122, enero de 1983, p. 64 


\section{El programa de comercialización fronteriza}

La insuficiente capacidad de la planta productiva nacional y de los canales de comercialización para lograr el objetivo de inundar la frontera de productos nacionales, provocó que la demanda por los productos norteamericanos por parte de los consumidores fronterizos mexicanos, prevaleciera.

A partir de 1970 y bajo la administración echeverrista, se implementó un nuevo mecanismo para acceder a la conquista de los mercados fronterizos. En lo fundamental, el objetivo del programa es retener a los consumidores fronterizos en el comercio local, e impulsar de nueva cuenta la concurrencia de productos nacionales a esta zona.

El programa denominado "Artículos Gancho", establece la libre importación de los artículos importados seleccionados, ya que estos serían sólo complementarios a los productos originarios del centro de la república, debiendo por tanto, mantener un nivel de precio accesible y similar al de los productos nacionales.

La forma de estimular la concurrencia de los productos nacionales a la frontera fue mediante la extensión del sistema de devolución de impuestos a las ventas realizadas a la frontera por empresarios nacionales. Por otra parte, se otorgaron estímulos consistentes en subsidios hasta por 10 años para los comerciantes amparados por el programa, lo cual era equivalente hasta un $100 \%$ de los impuestos de importación que gravaban a los artículos de consumo fronterizo seleccionados. Este estimulo se aplicó también a la importación de maquinaria y equipo y materiales de construcción.

Ahora bien, los requisitos para tener acceso a este tipo de estímulos eran contar con 100 \% de capital nacional, vender los productos importados a precios similares a los vigentes en los comercios fronterizos de E.U. vender como mínimo un $50 \%$ de productos nacionales, con el doble propósito de evitar que el consumidor fronterizo gastara su ingreso en el comercio estadounidense, y que con su consumo beneficiara tanto al empresario intermediario como al industrial nacional.

A su vez, la implementación de los Certificados de Devolución de Impuestos (CEDIS) jugó un importante papel, ya que estimuló a los productores nacionales a vender sus productos en la frontera norte, al devolvérseles la participación federal de los impuestos indirectos con que se gravaron sus productos. 20

Así, mediante estos instrumentos se logró introducir de manera efectiva una serie de artículos nacionales y, de nueva cuenta, durante los años 71-73, el índice de retención logra incrementarse en alrededor 2 centavos por año, decreciendo a partir de 1974, previo a la devaluación.

20J.L. Fernández, op. cit., p. 252. 


\section{Las devaluaciones.}

Al igual que los otros mecanismos, la política devaluatoria ha tenido como objetivo modificar la relación del consumo fronterizo en favor del empresario nacional. Pero no tan sólo del empresario comercial nacional como por excelencia lo es el empresario fronterizo, sino de la producción nacional.

En efecto, la política devaluatoria ha cumplido, entre otros, el papel de impedir el acceso a las importaciones por parte del consumidor nacional y su canalización al consumo de productos nacionales, otorgando así una inesperada competitividad al industrial mexicano que, en otras condiciones, no puede tenerla. Después de la implementación del PRONAF y del Programa de Artículos Gancho, el coeficiente de retención del ingreso fronterizo en el comercio local se mantiene siempre arriba del 30\% a su máximo incremento con $42.5 \%$. A partir de entonces, el ingreso retenido de cada dólar que ingresa a la frontera empieza a descender y, con la devaluación de 1976, justo cuando el coeficiente de retención está en su nivel más bajo deșde 1970, se incrementa (ver cuadro 1). Así, la devaluación contribuye a elevar el nivel de ingreso retenido por el empresario fronterizo al punto más alto que jamás se haya alcanzado.

Ahora bien, ¿que es lo que explica que la mayor parte del ingreso se canalice al consumo de bienes y productos ofrecidos en las ciudades fronterizas del sur de Estados Unidos?

El diferencial inflacionario de las economías mexicanas y norteamericana influye en el nivel de precios de las mercancías producidas y, cuando el nivel de precios es mayor en México que en Estados Unidos y el tipo de cambio es fijo, como ocurre hasta agosto de 1976, la propensión a importar se incrementa en relación directa al incremento del tipo de cambio real (ajustado por inflación).

En efecto, si el tipo de cambio real es mayor que el nominal, la propensión a importar será mayor, debido a que en términos del cambio de pesos por dólar, las mercancías norteamericanas son más baratas que las nacionales, que se encuentran influídas por la inflación interna y por la de los insumos importados incluidos en los costos de producción de estas mercancías.

La devaluación, desde la perspectiva del productor nacional,incrementa sus posibilidades de lograr mejores niveles de ganancia al hacer más competitivas sus mercancías en el comercio exterior y, en este caso, en la frontera. El empresario intermediario de la frontera también se beneficia con la devaluación, al colocar productos nacionales a mejor precio que los inesperada. mente incrementados precios de los bienes norteamericanos. Sin embargo, esta situación es meramente coyuntural para los productos nacionales, ya que debido al incremento permanente de la inflación en México, los productos del industrial nacional ven alejarse sus posibilidades de competen- 
CZADRO 2. Tipo de cambio nominal y real peso/dólar. (Base devalua. ción $=100$ )

\begin{tabular}{|c|c|c|c|c|c|c|c|}
\hline \multirow{2}{*}{$\begin{array}{c}\text { Año } \\
y \text { 'mes }\end{array}$} & \multirow{2}{*}{\multicolumn{2}{|c|}{$\begin{array}{l}\text { Indica- } \\
\text { dor }\end{array}$}} & \multirow{2}{*}{$\begin{array}{c}\text { Tipo de } \\
\text { cambio } \\
\text { nominal } \\
\text { libre }\end{array}$} & \multicolumn{3}{|c|}{$\begin{array}{l}\text { Movimiento de indices de precios al mayoreo } \\
\text { Base devaluación }=100^{* *}\end{array}$} & \multirow{2}{*}{$\begin{array}{l}\text { Tipo de } \\
\text { cambio } \\
\text { real }\end{array}$} \\
\hline & & & & México & Estados Uniत̄an & México/E.U. & \\
\hline & 1956 & & 12.50 & 100 & 100 & 1.000 & 12.50 \\
\hline & 1960 & & $12.5 !$ & 115 & 105 & 1.095 & 13.69 \\
\hline & 1965 & & 12.5 & 127 & 107 & 1.087 & 14.84 \\
\hline & 1970 & & $12.5 t$ & 146 & 123 & 1.087 & 14.84 \\
\hline & 1975 & & $12.5 \mathrm{C}$ & 244 & 194 & 1.258 & 15.72 \\
\hline & 1976 & & 15.44 & 100 & 100 & 1.000 & 15.44 \\
\hline & 1977 & & $22.5 \varepsilon$ & 141.1 & 108 & 1.306 & 29.49 \\
\hline & 1978 & & 22.77 & 163.2 & 116.4 & 1.402 & 31.92 \\
\hline & 1979 & & 22.81 & 193.3 & 129.1 & 1.497 & 34.15 \\
\hline & 1980 & & 22.95 & 240.4 & 147.7 & 1.628 & 37.36 \\
\hline & 1981 & & 24.51 & 299,3 & 161.3 & 1.855 & 45.47 \\
\hline enero & & & 26.43 & 348.1 & 166.1 & 2.096 & 55.40 \\
\hline febrero & & & 31.43 & 100 & 100 & 1.000 & 31.43 \\
\hline marzo & & & 45.27 & 104.1 & 99.8 & 1.043 & 47.22 \\
\hline abril & & & 45.95 & 110.6 & 99.8 & 1.108 & 50.91 \\
\hline mayo & & & 46.98 & 115.4 & 100,9 & 1.155 & 54.26 \\
\hline jụio & & 2 & 47.62 & 120.5 & 100.7 & 1.197 & 57.00 \\
\hline julio & & & 48.50 & 125.5 & 101. & 1.230 & 60.04 \\
\hline agosto & & & 83.75 & 100 & 100 & 1.000 & 83.75 \\
\hline septiembre & & & 70.00 & 102.7 & 99. & 1.030 & 72.10 \\
\hline octubre & & & 70.00 & 106.8 & 100. & 1.062 & 74.36 \\
\hline noviembre & & & 70.00 & 111.2 & 101. & 1.099 & 76.93 \\
\hline diciembre & & & 100.39 & 124.5 & 100.5 & 1.234 & 123.88 \\
\hline enero & & & 148.85 & 140.3 & 100.4 & 1.397 & 207.94 \\
\hline febrero & & & 148,65 & 148.2 & 100.4 & 1.476 & 219.41 \\
\hline marzo & & & 148.65 & 154.6 & 100.3 & 1.541 & 229.07 \\
\hline abril & & & 148.65 & 166.8 & 100.2 & 1.665 & 247.50 \\
\hline mayo & & & 148.65 & 181.2 & 100.6 & 1.801 & 267.72 \\
\hline junio & & \& & 148.58 & 189.7 & 100.9 & 1.880 & 279.33 \\
\hline julio & & $\Rightarrow$ & 148.36 & 197.7 & 101.2 & 1.954 & 289.90 \\
\hline agosto & & & 148.35 & 202.8 & 101.3 & 2.002 & 297.00 \\
\hline septiembre & & & 148.47 & 206.5 & 100.9 & 2.047 & 303.92 \\
\hline octubre & & & 151.34 & 211.5 & 101.2 & 2.090 & 316.35 \\
\hline noviembre & & & 155.31 & & & iv & \\
\hline
\end{tabular}

NOTAS: * Promedio

** Los cambios de base en función de las principales devaluaciones, han sido realizados mediante el uso de la técnica del empalme, según criterios en Núñez del Prado Benavente, Estadística Bárica para Planificación, Siglo XXI eds., México, 1982, p. 102.

FUENTES: De 1956 a 1975 Clark W. Reynolds, "Porqué el desarrollo estabilizador fue en realidad desestabilizador (con algunas implicaciones para el futuro)", en El Trimestre Económico, Vol. XLIV (4), No. 176, México, oct.-dic. de 1977, p. 104, cuadro 5.

Los tipos de cambio de 1975 en adelante provienen del Banco de México, Indicadores Fconómicos, México, diciembre de 1983 , p. IV -8 , cuadro IV-6.

Los índices de precios de 1976 a 1981 y de mayo a octubre de 1983 son del Banco de México, Boletin de lndicadores Económicos Intermacionales, Vol. IX, Núm. 4, México, oct.-dic. 1983, p. 55; los de 1982 son de ibid, Vol. VIII, Núm. 4, México, oct.-dic. 1982, p. 83 y; los de enero-abril de 1983 son de ibid, Vol. IX, Núm. 2. México, zbril-junio 1983, p. 67. 
cia respecto a los productos norteamericanos que no tienen tras de sí una inflacion tan elevada. Los empresarios intermediarios de la frontera también ven alejarse las posibilidades de incrementar su ganancia gracias al comercio de productos nacionales y vuelven, por tanto, al comercio de productos norteamericanos.

Como puede observarse, aquí se pone mucho énfasis en la relación de precios como elemento normativo que orienta el consumo fronterizo. En efecto, la intuición cotidiana permite afirmar que el consumo de los fronterizos del norte de México orientado hacia el mercado de productos norteamericanos -sean éstos adquiridos directamente en los centros comerciales de las ciudades fronterizas norteamericanas o en los centros comerciales de las ciudades fronterizas mexicanas-se realiza en función de que la población trabajadora fronteriza mexicana busca la defensa de su salario o cualquier otro tipo de ingreso que posea, que ante el implacable avance de la inflación, se ve permanentemente disminuido en términos de su poder adquisitivo.

Por esta razón, afirmar que el hecho de que la población fronteriza tenga preferencia por el consumo de productos norteamericanos es una actitud desintegradora y desnacionalizadora en el sentido señalado, es demostrar la ignorancia de la tendencia natural del trabajador por proteger y hacer rendir al máximo sus ingresos. Aún más, esta tendencia es tan objetiva que inclusive se observa en el comportamiento del trabajador fronterizo norteamericano.

A mayor abundancia, en 1979 el principal factor de atracción que tenían los productos norteamericanos sobre el consumidor fronterizo era su menor precio. Por lo menos esa es la principal razón que para acudir a comprar a San Diego Cal., tiene el 44 \% o de los consumidores de Tijuana. La mejor calidad de los productos es la razón de otro 29 o/o y; la mayor variedad y oportunidad es la razón del $37 \%$ o restante. 21

Lo anterior no significa otra cosa que la búsqueda por parte del trabajador fronterizo, de un mayor poder adquisitivo de su salario. Vistas así las cosas, el nacionalismo medido a través del innegable derecho de los trabajadores de buscar mejorar su nivel de vida, es un indicador injusto e ideologizante que pretende cubrir la ineficiencia productiva del industrial nacional para producir mercancías más baratas y competitivas que las norteamericanas como el principal instrumento para conquistar el mercado. Tras esto se encuentra la tradicional protección de ciertas industrias mexicanas por parte del Estado, que a la fecha se han convertido en una especie de parásitos sociales.

A decir de Stoddard, "Ia relación de interdependencia (entre ambas economías) es tan fuerte, que todos aquellos fenómenos económicos o me-

21Ramón Ramf́rez Acouxa y Franciuco Soto Angli (Coords.), "Caracterización del consumidor final fronterizo que a desplaza hacia los mercados de Escados Unidos", Cuedermos de Investigación del CIES, No. 1. Tïuana, 1979 , p. 15. 
didas de políticas económicas que tiendan a desvincular esta relación, sólo tendrán efecto en el muy corto plazo, normalizándose la relación después de un pequeño ajuste"..22

Un elemento extraeconómico que influye sobremanera en esta interdependencia fronteriza tanto de hombres como de productos, es "que la línea de demarcación internacional no separa poblaciones realmente diferentes en el plano regional", 23

En efecto, después de que con la devaluación de 1976 se alcanzó el más alto coeficiente de retención, a partir de entonces, el ingreso retenido por los empresarios fronterizos de cada dólar que ingresó a la frontera, ha tenido un franco descenso acuciado por el lacerante proceso inflacionario que tiene presencia en México y, para 1981, sólo 3.8 centavos de cada dólar que ingresa son retenidos por los empresarios fronterizos en términos de las compra/ventas realizadas.

De nuevo entonces,y en virtud de los diferenciales de inflación y el tipo de cambio nominal, la propensión a importar se va incrementando aceleradamente. Las devaluaciones de 1982 logran frenar el acelerado consumo fronterizo realizado en las ciudades de Estados Unidos. Sin embargo, el alto índice inflacionario de México tiende a que los productos mexicanos que hoy inundan la frontera, pierdan en el futuro su competitividad y que el consumo de la población de la frontera norte de México vuelva a reorientarse hacia los productos norteamericanos, aun cuando para ello fuera necesario recurrir al contrabando.

Esa es la interpretación de la relación entre la devaluación y la orientación del consumo fronterizo. Ahora bien, ¿qué es lo que ha pasado en estos ultimos años con los patrones de consumo de la población fronteriza de México y Estados Unidos?

En primer lugar, por primera vez en la historia fronteriza, el comercio se ha visto inundado de mercancías nacionales que, en las condiciones actuales, ha visto incrementado su nivel de ventas como nunca, pues ahora tiene que abastecer un inesperadamente incrementado mercado de consumidores locales que antes gastaban sus pesos en la ciudad fronteriza de E.U. y que ahora se ven obligados a comprar en el comercio local donde sus ingresos les rinden más. Además, hoy abastecen las necesidades de los consumidores norteamericanos que ven rendir más sus ingresos haciendo sus compras en los comercios de las ciudades fronterizas mexicanas. A manera de ejemplo, una ama de casa de National City que en E.U. compra su despensa familiar con 100 dólares, haciendo sus compras en Tijuana, lo hace con 30.

22 Ellwyn R. Stoddard, "El impacto de la devaluación del peso mexicano en la economía fronteriza de E.U.". citado por R, Ramírez y F. Soto, op, cit, P. 18. Paréntesis de AMM y PMM.

23j. Revel-Moróz, op. cit., p. 11. 
En consecuencia, el incremento de las ventas en la frontera obedece a la mejoría relativa de los precios de los productos nacionales en relación a los de los norteamericanos. Y aunque no debe perderse de vista que la competitividad viene dada por la devaluación y no por mejorías en la estructura productíva nacional, la coyuntura actual está brindando grandes ganancias a los industriales del centro del país y a la burguesía comercial (intermediadora) de la frontera.

En segundo lugar, estas elevadas ganancias tienen su contraparte en un deterioro sin precedentes del salario real de la fuerza de trabajo de la frontera norte de México. En efecto, paralelamente al descenso del coeficiente de retención que se da a partir de 1978 , el salario real de la fuerza de trabajo ha venido en franco descenso a partir de 1976.

La tendencia descendente del salario real es de vital importancia ya que ello indica la pérdida permanente de posibilidades materiales por acceder a un mínimo y decoroso nivel de vida. Tan sólo en el período transcurrido entre las dos grandes devaluaciones, el incremento de los precios ha sido del orden de $480 \%$ o; y para 1983 , es ya de $1047 \%$ o respecto a 1976 . En este último año, en tanto que el salario mínimo de un trabajador es de 455 pesos, el precio de un kilo de carne llegó a estar hasta 500spesos en la ciudad de Ensenada, B.C. Actualmente, el salario real de la clase trabajadora de la frontera norte de México es la mitad de lo que era en 1976. Dicho de otra forma, su nivel de vida en vez de mejorar se ha deteriorado en aproximadamente la mitad en tan sólo 7 años. Y esto no ha podido evitarse ni con loś incrementos salariales decretados para la zona. Como señala Carrillo, ahora sí que la orientación del patrón de consumo fronterizo hacia los productos nacionales, "se ha convertido en un recurso obligado y no conscientemente deseado". 24

Es claro que la orientación del consumo fronterizo hacia productos nacionales se ha dado por vías coercitivas mediante la afectación de los ingresos de la población trabajadora fronteriza, principalmente la que percibe el salario mínimo. Así, al incremento sin precedentes de las ventas de productos nacionales en la frontera, $y$ de las ganancias que ello ha retribuido a comerciantes e industriales nacionales, ha correspondido un descenso sin precedente del salario real de la fuerza de trabajo fronteriza.

\section{A MANERA DE CONCLUSION}

Si 1983 fue un año catastrófico para la población obrera y campesina de México, para los de la zona fronteriza del norte de México lo fue más, ya que profundizó aún más las desigualdades inherentes al proceso de desarrollo capitalista de la zona; las medidas devaluatorias y el proceso inflacionario tuvieron un impacto depredador en el poder adquisitivo de los secto-

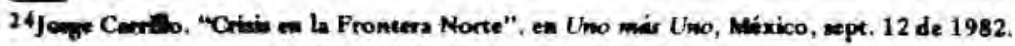


CUADRO 3. Salarios reales comparativos en municipios fronterizos: 1976 enero 1984. (Base $1976=100$ )

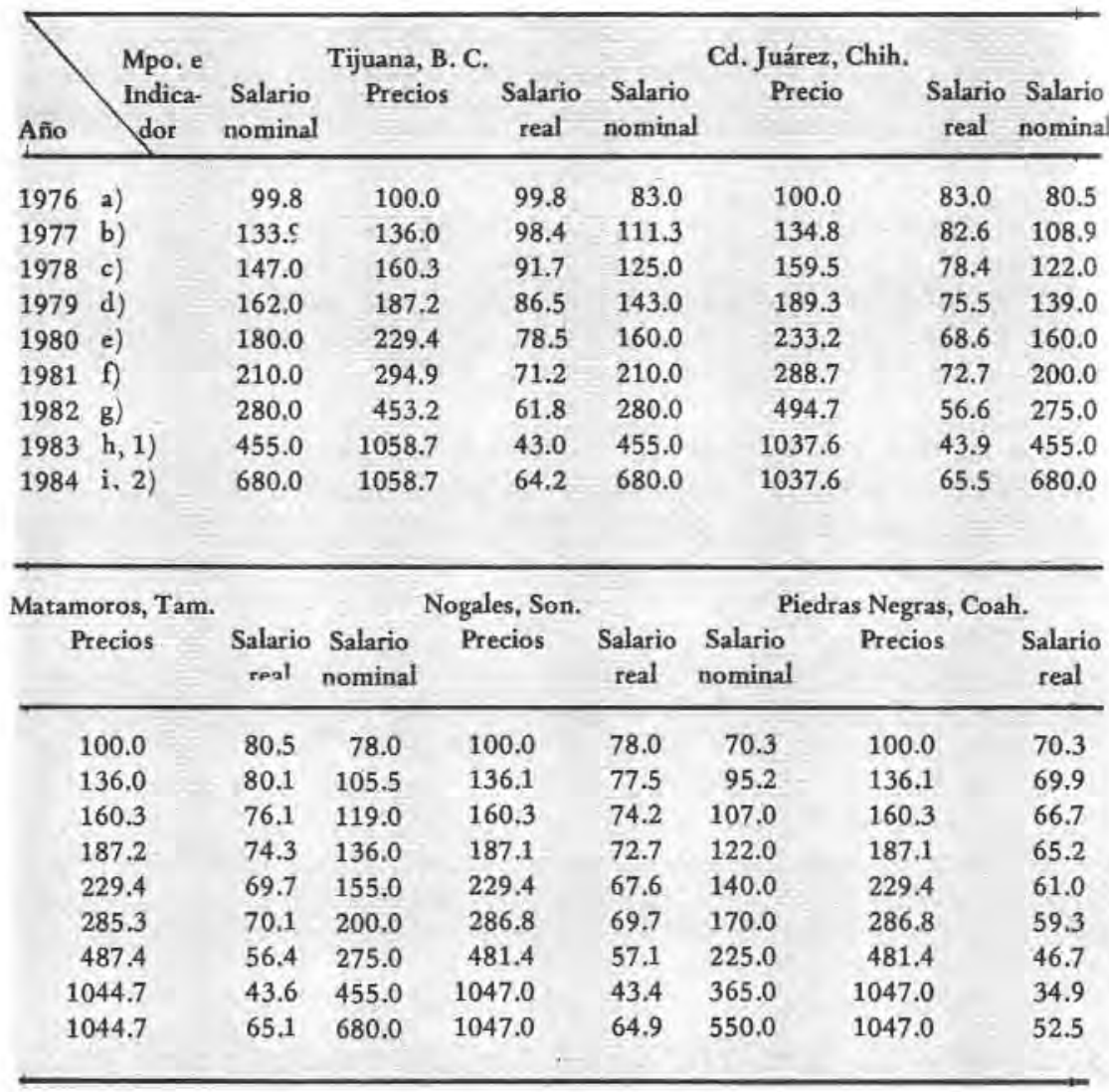

NOTA: 1) Los precios de 1983 son un promedio aritmético de enero a noviembre de 1983.

2) Los salarios nominales de 1984 se han deflactado a precios de 1983 para ver la recuperación de corto plazo del salario real

FUENTE: Para salarios mínimos:

a) Nafinsa, El Mercado de Valores. Año XXXV1, Núm. 3. México, enero 19 de 1976, p. 45.

b) Comisión Nacional de Salarios Mínimos. Salarios Mínimos 1977. México, febrero de 1977, pp. 27-30.

c) Nafinsa, op. cit,, Año XXXVIII, Núm. 2, México, enero 9 de 1978, p. 20.

d) Concanaco, Carta Semanal, No. 2075. México, marzo 26 de 1979, pp. 7-8.

e) Dirección de Promoción Económica e Industrial, Estudio Monografico de H. Matamoros, Tam. Gobierno del Estado de Tamaulipas, Tamaulipas, 1981, p. 17.

f) Concanaco, op. cit., No. 2172, México, enero 26 de 1981, pp. 9-10.

g) Nafinsa, op. cit., Año XLII, Núm. 2, México, enero 11 de 1982, p. 35.

h) Ibid. Año XLIII, No. 2, enero 10 de 1982 , p. 46.

i) Diario Oficial. Tomo CCCLXXI, No. 44, México, diciembre 30 de 1983, p. 11.

Para precios:

Banco de México, Indicadores Económicos. México, diciembre de 1983, pp. III. 9 y 111.10.

Para salarios reales:

Se obtienen deflactando el salario nominal con el índice de precios al consumidor. En el caso de Piedras Negras y Nogales, se ha utilizado el promedio fronterizo. 
FIGURA 1. Salarios reales y precios en la frontera de México. (Base $1976=100$ )

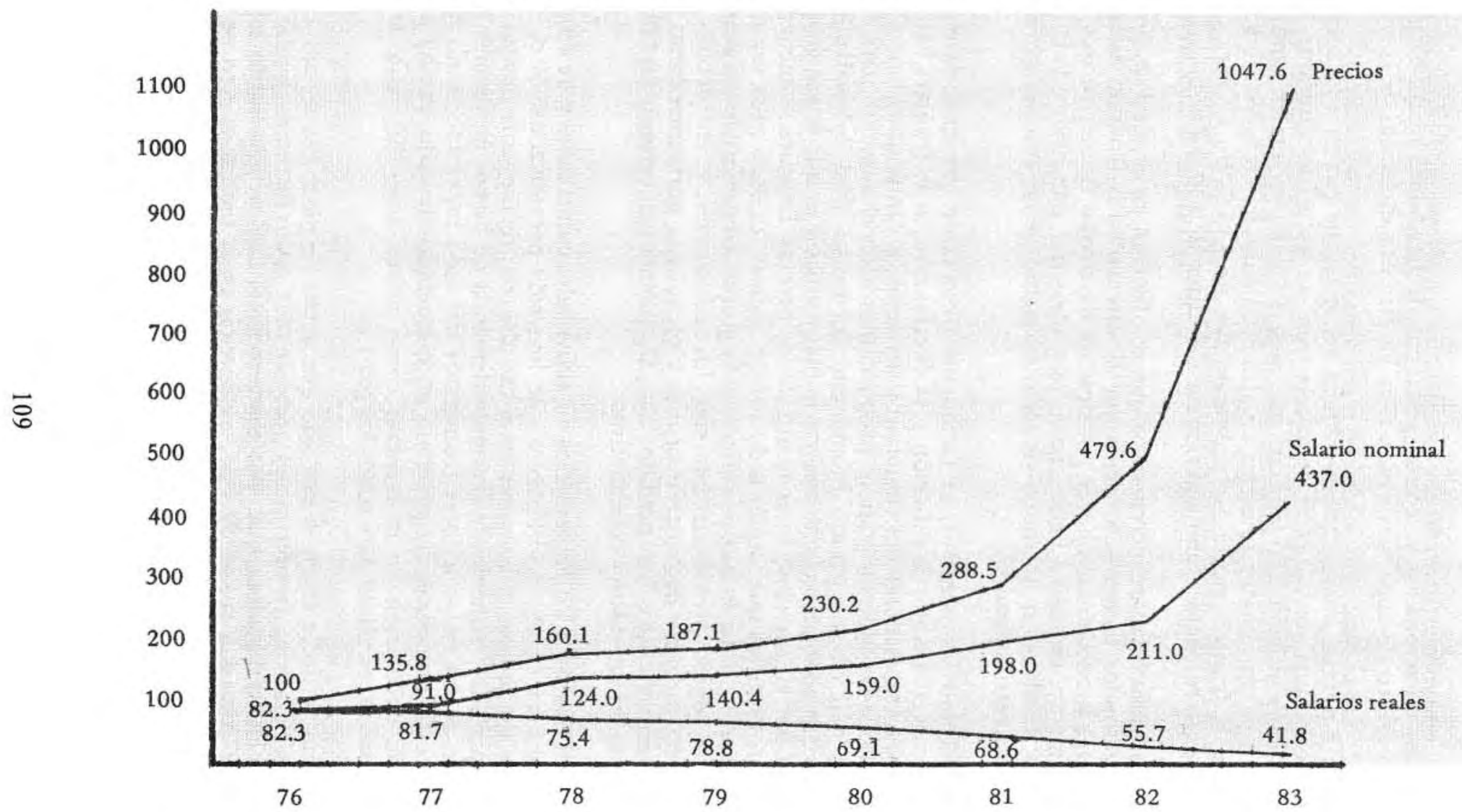

FUENTE: Elaborado en base a promedios. Ver entrevista de autores en PUNTO. México, febrero 13 de 1984. p. 6. 
res sociales mencionados y, contra todas las declaraciones manifiestas, un repentino efecto de auge inesperado para los grupos capitalistas de la región.

Esta hipótesis interpretativa pudiera ser más que eso, si a lo anteriormente dicho aunamos el hecho de que la frontera norte tuvo durante 1982 el crecimiento inflacionario regional más alto del país, ya que en tanto que los precios al consumidor tuvieron un alza promedio del $98.8 \%$ a nivel nacional, en la frontera norte ese promedio fue de $135.7 \%$ o.25 Para 1983. $\mathrm{el}$ incremento respecto al año anterior fue del orden de $117.3 \%$.

Estos desorbitantes incrementos que se observan en el nivel de precios de casi todos los bienes y servicios que se ofrecen en la frontera están sirviendo para fundamentar nuevas políticas de desarrollo fronterizo que, irremediablemente, tienden a beneficiar a los grupos que han hecho de la inflación y la devaluación un modo de vida, en virtud de las grandes ganancias que les está retribuyendo.

Aclarando los números, es fácilmente observable que quienes más se han visto afectados por la inflación y la devaluación en la frontera han sido los obreros, trabajadores del comercio y servicios, y campesinos, cuyo salario real ha descendido en grandes proporciones. Con el aumento para 1984, el salario real ha recuperado momentáneamente su nivel de mediados de 1981, ya que conforme el año avance, lo más probable es que se vea envuelto de nuevo por el acuciante incremento de los precios. Después se encuentran los sectores medios que, según todo parece indicar, tienden cada vez más a proletarizarse. Y en lo que se refiere a los grupos empresariales, si acaso algunos han tenido problemas, han sido los industriales, y eso debido a su enorme dependencia de materias primas y tecnología norteamericanas. Con todo, ni siquiera éstos han perdido: hay, sí, quienes han cerrado sus fábricas $o$ incurrido en actividades especulativas.

Y en cuanto a los empresarios en actividades comerciales y de servicios a estas alturas ¿quién podría creer que han sido perjudicados? Si el incremento de los precios al consumidor es tan alto, es precisamente porque ellos no han perdido. Además, la creciente demanda de bienes nacionales tanto por parte de los consumidores fronterizos del lado mexicano como de los del lado estadounidense, ha generado un inesperado mercado que ha propiciado una circulación de mercancías como nunca antes fue vista. Obviamente, esto no es válido para todos los giros.

Como se decía antes, si este año que acaba de pasar fue un año catastrófico para la zona fronteriza del norte de México, lo fue en particular para la población trabajadora que, por intermediación de su restringido salario, tiene que conseguir sus medios de subsistencia en el mercado; pero no para aquellos que, aprovechando la devaluación y el proceso inflacionario que le

25 Uno mís Uno, febrero 11 de 1983. 
acompañó, han puesto en el mercado a precios desorbitantes, las mercancías y servicios requeridos por la clase trabajadora.

Paradójico es entonces el significado del coeficiente de retención obtenido por los empresarios para 1982, que se recuperó notablernente. Esto quiere decir que cuando el mercado fronterizo en disputa presente una coyuntura favorable para los industriales nacionales y para la burguesía intermediadora de la frontera, será porque estos han afectado de la forma más abyecta a la clase trabajadora mexicana de la frontera; y aquí, no se podrá culpar al imperialismo. 